\title{
O duelo nas obras de Turguêniev e Flaubert
}

\author{
Samuel Junqueira Antoniasse ${ }^{1}$
}

\begin{abstract}
The gun duel was a constitutive element of the work of many Russian and French writers, reflecting its importance in the cultural history of both countries. The purpose of this article is to analyze how Ivan Turgenev and Gustave Flaubert used this theme in their works Fathers and sons and the Sentimental education. We intend to demonstrate that both writers, through the representation of the duel, sought to characterize the reality of his time.
\end{abstract}

Keywords: Turgenev; Flaubert; duel; Russia; France.

Resumo: O duelo de armas foi um elemento constitutivo da obra de muitos escritores russos e franceses, refletindo sua importância na história cultural dos dois países. O objetivo deste artigo é analisar de que modo Ivan Turguêniev e Gustave Flaubert utilizaram desse tema em suas respectivas obras Pais e filhos e A educação sentimental. Pretendemos demonstrar que ambos os escritores, através da representação do duelo, procuraram caracterizar a própria realidade de sua época.

Palavras-chave: Turguêniev; Flaubert; duelo; Rússia; França.

\section{Introdução}

Em setembro de 1861, após uma áspera discussão com Ivan Turguêniev, Liev Tolstói o desafia a um duelo. O pomo da discórdia teria sido um comentário do conde em que apontava incoerência no ato de fazer caridade e, ao mesmo tempo, trajar vestidos de última moda, numa clara alusão à filha de Turguêniev. O duelo terminou por não ocorrer, pois, definitivamente, participar de embates dessa natureza não era algo que conciliasse com o temperamento do sempre melindroso Turguêniev, o que não o impediu de ser um dos escritores russos que mais explorou tal fenômeno em suas obras. Em ao menos cinco delas Águas de primavera, Três retratos, $O$ duelista, Diário de um homem-supérfluo e Pais e filhos -, o tema assume importância fundamental dentro da trama, e em outras duas - Rúdin e Um

1 Bacharel em Letras (Português e Russo) pela Universidade de São Paulo (2012). Atualmente é mestrando no Programa de Literatura e Cultura Russa da mesma universidade. Contato: samjunqueira@gmail.com. 
mês no campo - ele é citado por um personagem como uma possibilidade a ocorrer.

Não somente Turguêniev, mas praticamente todos os grandes literatos russos do século XIX fizeram do duelo assunto de suas obras e muitos deles até o praticaram em vida, sendo Púchkin e Liérmontov mortos ao se baterem com seus respectivos rivais.

A apropriação geral desse tema pelos escritores pode dar a entender que o duelo seria um fenômeno genuinamente característico da sociedade russa. Ledo engano, pois sua chegada à Rússia e consequente expansão deram-se de forma muito lenta. Somente no início do século XIX, quando já entrara em declínio na Europa, é que o duelo começou a extrapolar as fronteiras de classe, ganhando a adesão da intelligentsia russa, o que ocasionou a popularização desse costume, que a princípio se restringia a uma elite aristocrática. Foram vários os fatores responsáveis por essa sua lenta assimilação entre os russos. Em seu período medieval, não houve na Rússia uma tradição de torneios de cavalaria, tão própria dos países europeus e característica da cultura do duelo. A própria noção de honra, tão cara às regras desse fenômeno, era estranha aos russos: "Nada entre as invenções estrangeiras soava mais ridículo aos russos do que o senso de honra e a tentativa de convencê-los a fazer, ou não, algo em sua causa" (Reyfman, 1999, 49).

Outro fator importante que retardou sua expansão foi a rígida legislação antiduelo. Ao longo dos anos foram promulgadas várias leis que proibiam sua prática e estabeleciam até mesmo a pena de morte aos transgressores. O czarismo via nesse fenômeno uma forma de afirmação do indivíduo, uma maneira de resolver os conflitos sem a intermediação do Estado, o que não podia ser bem visto em um modelo de governo tão centralizador quanto o russo.

Apesar de todos esses impedimentos, a prática do duelo encontrou um solo fértil na Rússia e se tornou um grande símbolo de sua cultura. O clima liberal do início do reinado de Alexandre I, assim como um maior contato com o Ocidente na campanha contra Napoleão em 1812, impulsionaram seu crescimento. A partir de então, não demorou muito para que os escritores russos, sempre atentos aos fenômenos sociais de sua época, procurassem representá-lo em suas obras.

Sem dúvida, a França foi o principal importador desse costume para a Rússia. Também no país europeu, a popularização deste fenômeno só ocorreu no início do século XIX: "Passado o período revolucionário, a instituição do duelo ganhou novamente força, dessa vez entre os novos ricos e principalmente entre os militares, apesar de não contar com a aprovação de Napoleão" (Figueiredo, 2007, 16). 
Porém, o alto status que o duelo atingiu na Rússia veio acompanhado de sua popularização, ao passo que na França ele perde seu glamour ao ganhar adeptos fora da elite aristocrática.

Assim como os russos, os escritores franceses não só exploraram o fenômeno em suas obras, mas também foram seus grandes defensores. Gustave Flaubert, ainda que não tenha feito de toda a sua obra uma vitrine para o duelo, foi um grande entusiasta dessa instituição. Diz Figueiredo:

Em seu Dicionário das ideias feitas, no qual pretendeu compilar as banalidades e lugares-comuns da burguesia de seu tempo, Flaubert dirigiu sua ironia não para os adeptos do duelo, mas para seus adversários. No verbete "Duelo", escreveu: "Combatê-lo; não é uma prova de coragem" (Figueiredo, 2007, 13).

Da mesma forma que em Turguêniev, é de surpreender essa inclinação do realista francês. Nada nos dois escritores, amigos e admiradores mútuos indica uma propensão para tal gosto. Além disso, é amplamente conhecido o caráter romântico do duelo, o que seria mais um motivo para os dois literatos terem por ele uma certa aversão, dado o estilo realista que caracteriza a obra de ambos. Mas nas duas obras os autores empregam este elemento constitutivo da narrativa exatamente para seus objetivos realistas: refletir a realidade social da época em seus países. O resultado final são duas cenas dignas de seus artistas.

\section{Pável Petróvitch e Ievguêni Bazárov: um duelo de gigantes}

Poucas obras causaram tanto alvoroço na sociedade russa quando de seu lançamento quanto Pais e filhos. É, sem dúvida, o romance mais importante de Turguêniev, pois marca o surgimento do mais polêmico "herói do tempo" da literatura russa. Desde a Revolta Dezembrista, em 1825, até 1861 - ano da libertação dos servos -, formou-se na literatura russa uma galeria de heróis que ficaram conhecidos como "homens supérfluos", designação dada por Turguêniev ao personagem da novela Diário de um homem supérfluo (1850). Entre eles destacam-se Evguiêni Oniéguin, do romance em versos de mesmo nome de Púchkin; Pietchórin, do romance Um herói do nosso tempo, de Liérmontov; Rúdin, de Turguêniev, e Oblomov, de Ivan A. Gontcharov, que marcou o ápice da representação desse tipo. Tal herói, idealista, mas inativo, não foi apenas uma invenção literária, mas o retrato mais acabado da 
própria realidade existente. A juventude nobre russa da metade do século XIX possuía uma grande capacidade intelectual e os mais elevados princípios morais. Todos aqueles jovens sentiam um desejo de mudança, de transformar o país, mas eram incapacitados para a ação, para a luta em nome de seus ideais. Isso se devia em grande parte à repressão a que estavam submetidos desde a Revolta Dezembrista, mas principalmente à educação aristocrática que receberam. Isaiah Berlin descreve a sociedade russa da época nos seguintes termos:

[...] uma Igreja semianalfabeta, dominada pelo Estado e enormemente corrupta; uma burocracia pequena [...] que lutava para controlar e refrear uma população enorme, primitiva, semi medieval, social e economicamente subdesenvolvida [...]; um sentimento generalizado de inferioridade social e intelectual em relação à civilização ocidental; uma sociedade distorcida por intimidações arbitrárias de cima e um repugnante conformismo e obsequiosidade no outro extremo, onde os homens que tivessem qualquer grau de independência, originalidade ou caráter dificilmente encontravam meios que lhe permitissem um desenvolvimento normal (Berlin, 1988, 265266).

Dessa forma, pode-se compreender a falta de perspectivas que marcou a juventude desse período na Rússia.

O próprio Turguêniev não era absolutamente dotado de uma natureza que o impelisse a sair empunhando uma bandeira. Em suas obras, questões como a abolição da servidão, as reformas sociais, aparecem apenas de forma indireta. Certamente que a censura se constituía como um obstáculo a qualquer atitude que pudesse ser caracterizada como "livre pensamento", mas ela por si só é insuficiente para explicar a prudência que Turguêniev manteve em suas obras durante toda a sua vida.

Em final dos anos 50 e início dos 60 do século XIX, começa a surgir uma nova geração, a chamada geração raznotchínetz, composta por jovens que não pertenciam à nobreza, mas que haviam tido acesso à universidade, e que se mostravam muito mais preparados para lutar por seus objetivos de justiça social do que os da geração anterior. Pais $e$ Filhos foi publicado no momento em que esta geração começava a aparecer. Turguêniev, ao caracterizá-la através da personagem Bazárov, viu-se atacado por todos os lados. Os conservadores acusaram-no de incentivar os jovens a promover a radicalização dos protestos então em voga, e estes acusaram o autor de ridicularizá-los através de Bazárov.

Turguêniev era um mestre na arte de provocar contra si reações tão parecidas em lados 
tão opostos. Isto acontecia pelo fato de ele se envolver em temas que suscitavam paixões virulentas sem marcar uma posição. Exímio observador que era, sua preocupação era representar uma realidade existente, ou pelo menos pressentida, e não defender uma causa. Manter a imparcialidade, num país onde o escritor era visto pelo povo como o verdadeiro guardião da Verdade, que indicava os rumos a serem seguidos, era uma tarefa muitas vezes difícil. Ao se recusar a apontar soluções e não tomar partido, Turguêniev ficava numa posição bastante vulnerável, sendo alvo de ataques de todos os lados. Foi o que ocorreu quando da publicação de Pais e Filhos. O autor russo criou um herói que, por suas atitudes e discursos, destilava polêmica, mas não deixou claro o seu ponto de vista sobre ele. O resultado não poderia ser outro: nenhum outro escritor russo viu-se tão caluniado e difamado quanto Turguêniev.

A trama do romance é bem simples: em um período de férias, o estudante Arkádi Kirsánov leva à sua casa o jovem médico pesquisador Bazárov. O tio de Arkádi, Pável Petróvitch, é um típico representante da geração da década 1840, um nítido homem supérfluo. Não demora muito para que se instale um conflito ocasionado pelas ideias conservadoras de Pável - ainda que com um matiz liberal - e as concepções radicais e arrogantes de Bazárov. Portanto, o primeiro duelo entre os dois não é o de armas em campo aberto, mas o de palavras na mesa de jantar, pois são nessas "reuniões familiares" que ficam evidentes as diferenças entre o tio e o amigo de Arkádi. Esse duelo de ideias meio que prenuncia o duelo de armas. Vale citar o trecho em que Pável Petróvitch é informado de que Bazárov seria um niilista:

- O que Bazárov é? - sorriu Arkádi. - Tio, o senhor quer que eu lhe diga o que ele é precisamente?

- Faça-me esse favor, sobrinho. - É um niilista.

- Como? - perguntou Nikolai Petróvitch, enquanto Pável Petróvitch se punha imóvel, a faca erguida no ar com um pouco de manteiga na ponta da lâmina (Turguêniev, 2004, 46).

Percebe-se aqui a genialidade de Turguêniev. Justamente no momento em que toma conhecimento desse caráter do jovem médico, o velho dândi está com "a faca erguida no ar". Uma pequena representação que já indica uma luta de morte entre eles. 
Ainda que a decisão de Pável Petróvitch de se bater com seu rival somente se concretize após vê-lo em um momento de intimidade com a jovem esposa de seu irmão Nikolai, o duelo não é por uma questão passional. Tal fato se torna apenas uma gota d'água num copo transbordante, tanto que Pável nem se vê na obrigação de, no momento em que o desafia, revelar a Bazárov o que presenciara sob os caramanchões. Diz ele: "Eu poderia lhe explicar o motivo [...]. Mas prefiro silenciar a respeito. Para o meu gosto, aqui não há lugar para o senhor; não consigo suportá-lo, sinto desprezo pelo senhor e, se isto não for o bastante..." (Turguêniev, 2004, 224).

O fato de Bazárov aceitar o desafio intrigou muitos críticos. Que Pável Petróvitch fosse a campo para duelar é algo compreensível. É um homem apegado aos velhos valores aristocráticos, e o duelo, apesar de sua popularização, nunca deixou de ser um. Mas Bazárov participar de algo originário de uma classe que ele abomina? À primeira vista, parece soar incoerente com tudo o que afirmara anteriormente. Mas, na verdade, o jovem radical, ao aceitar o desafio, procura manter seus princípios. O que ele aprecia no duelo não é o seu caráter aristocrático, mas sua funcionalidade. Diz ele: “[...] Do ponto de vista teórico, o duelo é um disparate; mas, do ponto de vista prático, a questão muda de figura" (Turguêniev, 2004, 224).

Materialista ao extremo, ele vê uma utilidade racional no duelo: tirar satisfação de uma ofensa. O romantismo e as formalidades que caracterizam a instituição, ele os despreza. Pável Petróvitch sabe disso, daí o fato de concordar com seu rival em abrir mão de todo acessório romântico que acompanha tal fenômeno: padrinhos, discórdia formal, bilhete de despedida isentando o adversário de qualquer responsabilidade no caso de morte etc.

O cenário do duelo é uma imagem clichê desse tipo de ocorrência: um bosque afastado em uma manhã "agradável e fresca". O contraste é proposital: contrapor uma natureza esplêndida indiferente ao horror da ação humana.

Inicia-se o duelo. O primeiro a atirar é Pável Petróvitch. A bala passa zunindo na orelha do rival. Mandaria a boa conduta que, por não ter sido atingido, Bazárov atirasse para o alto. Porém, pouco preocupado com as regras formais, ele mira no alvo e acerta de raspão a coxa de seu adversário, que se mantém de pé. Sua reação, é, como médico, sair em socorro do ferido. A partir daí, há uma mudança de comportamento nos dois personagens. Os diálogos rancorosos anteriores dados na mesa de jantar, impregnados de sarcasmo, displicência e agressividade, dão lugar a uma conversa amigável entre dois cavalheiros que, ainda que não 
suportem um ao outro, procuram manter um respeito mútuo.

Há, sem dúvida, um referencial alegórico nessa cena do duelo. Bazárov atinge, mas sequer derruba Pável Petróvitch. É como se aqueles novos homens da geração de 1860 possuíssem uma força, mas insuficiente para destruir os alicerces da aristocracia. Estes continuam firmes, apesar dos tiros que recebem. Longe de ver no ato de socorrer o ferido uma magnanimidade ou uma responsabilidade profissional do jovem médico, o que o leitor vê é uma capitulação por parte do jovem radical. Bazárov sai moralmente derrotado do duelo, apesar de não ter sido atingido. Se antes do embate ele era admirado por grande parte dos criados dos Kirsánov, após a luta ele passa a ser menosprezado. Sua única opção é voltar à casa dos pais e trabalhar como um simples médico de aldeia. Destino trágico para alguém que sonhava virar a Rússia de cabeça para baixo. Nos lábios de Pável Petróvitch, impossível não notar um sorriso de satisfação.

\section{Frédéric Moreau e o Senhor de Cisy: a farsa de um duelo}

Se entre Pável Petróvitch e Bazárov há um duelo de gigantes, de dois homens convictos de seus ideais, daquilo que representam, em A educação sentimental o duelo é entre dois jovens desprezíveis, dotados da mesquinha mentalidade burguesa da metade do século XIX: Frédéric Moreau e o Senhor de Cisy, que possui o título de visconde.

Os dois personagens de Pais e filhos não abrem mão daquilo em que acreditam, mesmo diante das mais terríveis adversidades. Seguem sempre um caminho reto, olhando com desdém para seus desvios. Já com Frédéric e o visconde - e com a maioria dos personagens de Flaubert - não há um ideal incontestável a ser seguido, pois estão sempre flutuando conforme a conveniência. Com Frédéric, há até mesmo uma extrapolação dessa característica. A todo momento, ele oscila entre um e outro objeto. Isso é bem nítido no campo amoroso - em que, ao menor sinal de contrariedade, abandona uma amante e retorna à outra -, mas ocorre em todos os níveis de suas relações: nas artes - quer escrever um romance, quer ser pintor, mas sempre desiste -; na profissional - pretende seguir carreira pública, mas cede ante os primeiros obstáculos -; no círculo de amizades: está sempre alternando entusiasmo e desilusão em relação aos amigos.

Já o Senhor de Cisy é uma versão ainda piorada de Frédéric, a ponto de este considerálo um "néscio". Se Frédéric, mesmo com todo o seu caráter hesitante, não se constrange em 
envolver-se com mulheres casadas ou que tenham amante, o visconde não ousaria tanto. Diz o narrador: "[...] o jovem aristocrata lançava olhares às mulheres, mas [...] não se atrevia a dirigir-lhes a palavra, imaginando que, em casa de tais mulheres, havia sempre 'um homem escondido no armário, com uma pistola, e que surge a exigir a assinatura de letras'" (Flaubert, 1959, v. 1, 90).

Criado sob os austeros valores aristocratas, não são por estes que ele sente mais afeição. Principalmente após a morte da avó - por quem fora educado -, adotara costumes alheios à educação que recebera. Vale citar um trecho que mostra de modo exemplar o seu novo comportamento:

Desde que acabara o luto pela avó, realizava o seu ideal, conseguia ter 'estilo'. Colete escocês, casaca curta, calça de boca de sino sobre os escarpins, o bilhete de entrada metido no chapéu, nada faltava, com efeito, ao que ele chamava o seu 'chique', um chique anglômano e à mosqueteiro. Começou por se queixar do Champ de Mars, turfe execrável, falou depois das corridas de Chantilly e das brincadeiras que lá se faziam, jurou ser capaz de beber doze taças de champanha enquanto batiam as doze badaladas da meia-noite, sugeriu à Marechala que apostasse, e acariciava os dois cachorrinhos; e, apoiando-se com o outro cotovelo na portinhola, continuava a dizer tolices, metendo na boca o punho do pingalim, de pernas abertas, aprumando-se muito (Flaubert, 1959, v. 2, 46).

É um comportamento que soa artificial, não é algo que se amolda com a sua frágil e sensível pessoa. Com tudo isso, já é possível imaginar o que seria uma cena de duelo entre dois personagens tão... interessantes. E Flaubert não nos decepciona.

A rusga entre Frédéric e o visconde começa na cena do Hipódromo, com o último procurando fazer a corte junto à personagem Marechala. Sendo, por ele, convidada para jantar, ela o dispensa. Flaubert lança uma pequena intriga para já deixar indispostos os dois personagens.

Porém, no mesmo dia, no Café Anglais, estando Frédéric e a Marechala sentados a uma mesa, Cisy se aproxima e junta-se a eles. Seu simples aparecimento incomoda nosso protagonista e a desavença entre ambos vai ficando mais evidente. Assim como em Pais e filhos, o desentendimento entre os personagens dá-se à mesa, no momento de uma refeição, mas com que diferença. Se com Pável Petróvitch e Bazárov a altercação gira em torno de altas questões e torna-se uma discussão intelectual em que os grandes dilemas da Rússia são debatidos com fervor por dois personagens bastante diferentes, mas fiéis aos seus princípios, 
entre Frédéric e Cisy a discussão é em torno de temas banais e fúteis, destituídos de qualquer importância intelectual. A primeira desavença entre eles é sobre o momento apropriado para se tomar borgonha, se antes ou após as refeições; em seguida há uma discussão acerca de qual seria o sistema de equitação mais eficiente; por último, a linhagem - nobre ou não - da Senhora Dambreuse torna-se motivo de discórdia. Não se poderia exigir mais de ambos, pois estamos na França, às vésperas da malfadada República de 1848, não na Rússia efervescente de 1860.

O fato de a Marechala sempre apoiar o ponto de vista de Cisy e ir embora em seu fiacre só aumenta a antipatia de Frédéric pelo jovem aristocrata. Dessa forma, ela já se desenha como o pivô de uma contenda. Nesse momento, Flaubert lança um indicativo da possibilidade da ocorrência de um duelo. Diz o narrador: "Frédéric teve vontade de esbofeteálo" (Flaubert, 1959, v. 2, 18). E poucas linhas depois: "Frédéric passou o dia seguinte a ruminar a sua cólera e a sua humilhação. Lamentava não ter esbofeteado Cisy" (Flaubert, 1959, v. 2, 18). Explica-se: esbofetear uma pessoa era tido como a forma mais eficaz de desafiá-la. Diz Reyfman: “[...] um tapa no rosto era parte integrante dos rituais dos duelos do Ocidente. De acordo com os códigos de honra do século XIX, um tapa constituía-se na mais grave ofensa contra a honra e era uma forma de provocar o duelo” (Reyfman, 1999, 108). Há, então, ainda que inconscientemente, esse desejo por parte de Frédéric.

Mas, em A educação sentimental, nada aparenta ser duradouro. Essa desavença entre os dois personagens se desmancha com um simples encontro cordial na rua, no qual Cisy convida Frédéric para jantar. Mas o que parecia ser um jantar de reconciliação termina por se constituir em uma oportunidade para o visconde gabar-se perante seu rival. Fica evidente que essa fora a sua intenção desde o início, e não uma possível reconciliação, como o leitor pensa inicialmente.

No jantar, dá-se um festival de ofensas a todos aqueles que são caros a Frédéric. A Marechala é tida como uma mulher que se vende, seu amigo Arnoux, "uma espécie de vigarista", e quanto a Senhora Arnoux, além de lhe trocar o nome, o visconde diz que a frequenta. Exasperado, Frédéric atira-lhe um prato, o que motivará os amigos de Cisy, também presentes no jantar, a desafiar nosso protagonista a um duelo. Como em todo o romance, há nessa cena um processo de substituição para algo menor. O desejo de Frédéric, como registrado anteriormente, era dar um tapa na cara do visconde, mas termina por lançar um prato em seu ventre, que, ao atingi-lo, já o faz quebrado em três partes e somente depois 
de chocar-se com garrafas e compoteiras.

Nem mesmo o porquê de Frédéric jogar o prato sabe-se ao certo. Diz o narrador: "Como, no momento em que o prato fora lançado, todos falavam ao mesmo tempo, não foi possível descobrir o motivo daquela ofensa, se era por causa de Arnoux, da Senhora Arnoux, de Rosanette ou de outra pessoa" (Flaubert, 1959, v. 2, 27).

Foi preciso até mesmo consultar militares para determinar quais foram o ofensor e o ofendido. Se em Pais e filhos os dois rivais batem-se convictos, sem lamentar a decisão tomada, aqui Frédéric e Cisy preferiam no fundo não se enfrentarem, desejando até mesmo que suas testemunhas pedissem desculpas, sem consultá-los, claro. Por tudo isso, é um duelo que já nasce desacreditado. As testemunhas, a discussão minuciosa das regras, as formalidades tomadas, tudo isso apenas tenta passar um verniz de seriedade a algo que, desde o princípio, soa ridículo. No romance de Turguêniev, dispensa-se qualquer espécie de cerimônia, porém ninguém duvida da seriedade do acontecimento.

$\mathrm{Na}$ cena do duelo, Flaubert não escapa de fazer a descrição clichê da esplêndida natureza indiferente à ação humana: "O céu estava azul, e de quando em quando ouvia-se saltar uma lebre" (Flaubert, 1959, v. 2, p. 33). Mas o grande realista francês não se contentaria com tão pouco. Essa natureza exuberante, que, aparentemente, não interfere nos atos do homem, é a mesma que alerta para seus horrores: "Um raio de luz, atravessando as folhas, caiu sobre elas (as espadas), e pareceu aos olhos de Cisy que brilhavam como víboras de prata sobre uma poça de sangue" (Flaubert, 1959, v. 2, 34).

Flaubert também faz de objetos inanimados prenúncios daquilo que pode ocorrer: "O Senhor de Comaing tinha uma bengala na mão. Houve um silêncio. Entreolharam-se. Em todos os rostos havia algo de assustador ou de cruel" (Flaubert, 1959, v. 2, 34). É como se a bengala, instrumento que revela uma deficiência por parte de seu portador, indicasse os possíveis resultados daquele embate.

O duelo, de espadas, inicia-se. Mal ouve a ordem para avançar, Cisy cai desmaiado. Se um tiro não é suficiente para derrubar Pável Petróvitch, aqui nem é preciso uma estocada para causar um estrago ainda maior. Chega a ser hilário quando alguém anuncia que o visconde está sangrando. O narrador confirma a informação: "Com efeito, ao cair, esfolara o polegar da mão esquerda" (Flaubert, 1959, v. 2, 35) Ou seja, o ferimento do visconde não é resultado de sua participação na luta - o que revelaria coragem -, mas de sua não participação - o que revela covardia. 
De repente, Arnoux aparece e encerra o embate antes mesmo de ele começar efetivamente. Os rivais reconciliam-se e cada grupo vai para o seu lado. Dessa forma, a cena do duelo está situada no universo do não consumado, que é o universo de grande parte dos acontecimentos de A educação sentimental. Ao contrário do que ocorre em Pais e filhos, na obra de Flaubert o duelo não apresenta nenhuma importância para o desenvolvimento da trama. Não faria falta alguma ao romance, passaríamos bem sem ele, se não fosse a maestria de Flaubert ao descrevê-lo.

\section{Referências bibliográficas}

Berlin, Isaiah. "Pais e filhos: Turguêniev e a crítica situação liberal". In: Berlin, Isaiah. Pensadores russos. São Paulo: Companhia das Letras, 1988, 262-298.

Reyfman, Irina. Ritualized violenve russian style: the duel in russian culture and literature. California: Stanford University Press, 1999.

Figueiredo, Cláudio (org). "Introdução", In: Figueiredo, Cláudio. Mestres-de-armas: seis histórias sobre duelos. São Paulo: Companhia das Letras, 2007, 7-30.

Flaubert, Gustave. (1869) A educação sentimental. São Paulo: Difel: 1959, vol. 1 e 2.

Turguêniev, Ivan. (1862) Pais e filhos. São Paulo: Cosac \& Naify, 2004. 